\title{
Surgical plume and its implications: A review of the risk and barriers to a safe work place
}

Follow this and additional works at: https://www.journal.acorn.org.au/jpn

Part of the Health Services Administration Commons, Health Services Research Commons, Perioperative, Operating Room and Surgical Nursing Commons, and the Surgery Commons

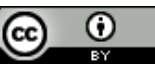

This work is licensed under a Creative Commons Attribution 4.0 License.

\section{Recommended Citation}

Tan, Eunice and Russell, Kylie P. (2017) "Surgical plume and its implications: A review of the risk and barriers to a safe work place," Journal of Perioperative Nursing: Vol. 30 : Iss. 4 , Article 2.

Available at: https://doi.org/10.26550/2209-1092.1019

https://www.journal.acorn.org.au/jpn/vol30/iss4/2

This Article is brought to you for free and open access by Journal of Perioperative Nursing. It has been accepted for inclusion in Journal of Perioperative Nursing by an authorized editor of Journal of Perioperative Nursing. 


\section{Authors}

Eunice Tan

Masters of Nursing student, School of Nursing \& Midwifery, The University of Notre Dame Australia

Dr Kylie Russell

PhD, MHlthSc(Ed), BN, RN

Postgraduate Coordinator, School of Nursing \& Midwifery, The University of Notre Dame Australia

\title{
Surgical plume and its implications: A review of the risk and barriers to a safe work place
}

\author{
Abstract
}

Every year thousands of health care professionals worldwide are exposed to surgical smoke. There is evidence that this smoke consists of toxic gases, pathogens and particulate matter that is a hazard for patients and the perioperative team. Past research indicates that perioperative staff inconsistently comply with smoke evacuation recommendations. The aim of this study was to identify, review and discuss the issues related to surgical plume and its implications for patients and perioperative staff. The findings of this review relate to: surgical smoke content, its risks to the health of the perioperative staff, preventative measures, infection control measures, compliance with smoke evacuation systems, staff knowledge and barriers to implementing smoke evacuation practices. Of particular importance, the literature indicated that strong support from management and the implementation of regular staff education could improve practice for the management of surgical plume in the operating theatre.

\section{Introduction}

Surgical plume, also known as surgical smoke, cautery smoke, smoke-plume, diathermy plume, aerosol, bio-aerosol, vapour and air-contaminants ${ }^{1,2}$, is a dangerous by-product produced by the electrosurgical instruments used to dissect tissue, provide haemostasis and perform laser ablation. These instruments include electrosurgery units, lasers, ultrasonic devices, high speed drills, burs and saws that produce heat and allow the surgeon to achieve the desired tissue effect ${ }^{3,4}$. Surgical plume is created by the thermal damage of tissue which releases cellular fluid as steam and spews cell contents into the air. Chemical analysis lists its constituents to be 95 per cent water vapour and 5 per cent other chemicals and cellular fragments ${ }^{5}$. Surgical plume can pose health risks to thousands of health care workers on an annual basis ${ }^{6}$. This article provides a review of the contemporary literature in relation to surgical plume, its composition, the risks it creates and management strategies.

\section{Background}

In this review, the authors aimed to identify, review and discuss the issues related to surgical plume and its implications for patients and perioperative staff. Health professionals in the perioperative environment are routinely exposed to surgical smoke, plume and aerosols produced by instruments used to dissect tissue and provide haemostasis. This can pose significant health risks, in particular for nurses and anaesthetists who spend more time in the operating room than ancillary workers, such as 
orderlies, and surgeons because of clinic or ward schedules ${ }^{3}$. Strategies to educate perioperative staff about the risks and the use of smoke evacuation systems are essential for improved health outcomes.

Research has shown conclusively that surgical smoke is hazardous to personnel who are exposed to it daily ${ }^{2,3,7}$ and hence concerns have been raised regarding the infective, mutagenic and cytoxic properties of surgical smoke from all the aforementioned devices?.

According to the Association for Perioperative Practice ${ }^{8}$ and Ulmer ${ }^{2}$, surgical smoke is always present and it forms part of the patient-care environment whenever surgical or invasive procedures are performed. Surgical plume consists of 95 per cent water and 5 per cent other matter containing chemicals, dead and live cellular material (blood fragments, bacteria, viruses), toxic gases, vapors (e.g. benzene, hydrogen cyanide, formaldehyde) and lung-damaging dust 2,3,5,-11. These components of the surgical plume are classified as 'physical', 'biological' and 'chemical'.

The physical component consists of particles that range in size from less than 0.01 microns to more than 200 microns 1 . The largest particles $(0.35$ microns to 6.5 microns) are produced by ultrasonic devices, laser ablation produces particles of 0.3 microns and electrocautery produces particles of less than 0.1 micron. These ultrafine particles create a very fine dust ${ }^{1}$ and anything less than 0.3 microns is able to bypass the lungs normal filtration mechanism and deposit in the alveolar region ${ }^{1,7}$. Particles that settle in the tiny air sacs transfer biological material and possibly cause infection, congestion and aggravation of conditions such as chronic obstructive pulmonary disease and asthma ${ }^{6}$. Repeated inhalation of surgical smoke can induce acute and chronic inflammatory changes including congestion, pneumonia, bronchiolitis and emphysematous changes in the respiratory tract ${ }^{4}$.

The biological component of surgical plume contains blood and potentially infectious viruses and bacteria. Examples of known contaminants include human immunodeficiency virus (HIV), human papillomavirus (HPV), bovine papillomavirus (BPV) and possibly hepatitis virus s,10,12-14 $^{\text {. }}$

The chemical component of surgical plume contains more than 80 different toxic chemicals and byproducts $^{13}$, including:

- acrolein (a known carcinogen)

- acetonitrile

- acrylonitrile (long term exposure causes cancer)

- acetylene

- alkyl benzenes

- benzene (a known carcinogen)

- butadiene (a known carcinogen)

- butene

- carbon monoxide

- creosols

- ethane

- ethylene

- formaldehyde (a known carcinogen, used to preserve surgical specimens and as an embalming fluid)

- free radicals

- hydrogen cyanide (neurotoxin used in chemical warfare, is cardio-toxic)

- isobutene

- methane

- phenol

- polycyclic aromatic hydrocarbons

- propene
- propylene

- pyridine

- pyrrole

- styrene

- toluene (a known carcinogen)

- xylene $3,12,13,15$.

\section{Methodology}

An integrative review is an examination of research that amasses comprehensive information on a topic, weighs pieces of evidence and integrates information to draw conclusions about the state of knowledge ${ }^{16}$. An integrative review in health care synthesises the results of several carefully designed studies on a specific question and provides a high level of evidence on the effectiveness of the health care intervention/s. Judgements may be made about the evidence to inform health care practice.

These reviews are detailed examinations of the available research; they are therefore only as effective as the research that they report on. Reviewers evaluate the evidence to determine an overall view of the practice/treatment in question. In this way, integrative reviews are able to summarise the existing clinical research on a topic ${ }^{17,18}$.

A search was undertaken for studies and journal articles related to the risks of surgical smoke, chemical composition of surgical smoke, potential hazards of surgical smoke, implementing surgical smoke evacuation in the operating room and staff education. The author used Cochrane, PubMed and Google scholar databases to search for studies between 1990 and the present. Additional information was extracted from surgical textbooks, manufacturer's websites and government and non-government 
agencies, such as the Australian College of Operating Room Nurses (ACORN), Association of periOperative Registered Nurses (AORN) and Association for Perioperative Practice (AfPP).

\section{Findings}

The findings of this study relate to the risks associate with surgical plume, the measures taken to prevent these risks and compliance with implementing preventative measures.

\section{Risks}

According to Ulmer ${ }^{2}$, surgical smoke can be seen and smelled and these visible and odorous components of surgical smoke are the gaseous by-products of the disruption and vaporisation of tissue protein and fat. Surgical smoke has been described as being a nuisance at the very least and, at worst, carcinogenic ${ }^{2,10}$. Additionally the carbon monoxide generated during electrocautery can cause headaches, burning and watery eyes, nausea and respiratory problems'. These components irritating the lungs have a similar mutagenicity to cigarette smoke ${ }^{1,19}$. Recent studies quantified the average daily exposure of surgical smoke in the operating room as equivalent to 27 to 30 cigarettes $^{4,19}$ and the ablation of 1 gram of tissue as creating surgical plume with the mutagenic effect of smoking six unfiltered cigarettes $^{12,19}$. Benson et al. ${ }^{9}$ confirm that particles smaller than 5 microns are categorised as lung-damaging, and can result in acute and chronic respiratory changes which include emphysema, asthma and chronic bronchitis. Nascent Surgical ${ }^{20}$ highlighted that poorly maintained theatre environments resulted in an increase in staff absenteeism and decreased productivity due to acute respiratory illness.
Studies with mice and rats have highlighted these significant health risks. Baggish and associates ${ }^{21}$ compared the effects of unfiltered laser smoke on rats' lungs. They all developed hypoxia and pulmonary congestion with bronchial hyperplasia and hypertrophy. A comparison control group were subjected to filtered plume, with no lesions identified ${ }^{3}$. Another study using mice showed that melanoma cells were released into the surgical plume after application of electrocautery to malignant tissue ${ }^{14}$, these cells were viable and cultured ${ }^{22}$ demonstrating that an organism can survive electrocautery ${ }^{23}$.

In addition to airborne contamination, Ulmer ${ }^{2}$ and Ball ${ }^{15}$ note that surgical smoke has a potential risk for patients during laparoscopic surgery and endoscopic procedures whereby the contaminants of the surgical smoke are absorbed into the patient's vascular system.

Concerns about the danger of surgical smoke are not new. In fact, 22 years ago concerns were raised that smoke absorbed through the peritoneal membrane resulted in an increase in methaemoglobin and carboxyhaemoglobin in the blood stream. This effect reduces the oxygen capacity of red blood cells, producing falsely elevated oxygen readings that could result in unrecognised patient hypoxia 2,12.

\section{Electrocautry devices}

According to Weld et al. ${ }^{24}$, comparisons of bipolar, ultrasonic and monopolar devices found that monopolar devices produce the most surgical plume, impeding surgical visibility to the greatest extent.

Electrocautery devices and lasers heat target cells to the point of boiling, causing cells to rupture and disperse fine particles into the atmosphere. By comparison, ultrasonic devices use a vibrating plate to cause cell rupture at a much lower temperature, causing cutting and coagulation simultaneously without an electrical current passing though the tissue?.

The literature has described that plume generated from laser surgery and electrosurgical cautery contains viable infectious particulate matter such as HPV, HIV and hepatitis B virus (HBV). Studies have reported that these infectious viruses can be transmitted to the upper respiratory tract through inhalation of surgical smoke. A case report published in 1991 revealed that a 44-year-old surgeon had developed laryngeal papillomatosis after using a laser to vaporise condyloma (Ball 2001). Another case report in 2013 reported the direct correlation between the developments of tonsillar cancer in two gynaecological surgeons and their exposure to surgical plume containing HPV 16 cells $^{25}$.

\section{Preventive measures}

\section{Evacuation}

Lewin et al. ${ }^{10}$, Ball ${ }^{3}$, Bigony ${ }^{22}$ and AfPP $^{8}$ advocate the use of smoke evacuators and personal protection equipment (PPE). According to $\mathrm{Ball}^{3}$, there are a variety of smoke evacuators available depending on the amount of plume generated. An in-line smoke evacuator filter is appropriate for smaller amounts of plume while an individual smoke evacuator, which usually has a triple filtration system that includes a pre-filter, a charcoal filter and an ultra-low penetration air (ULPA) filter, is used if larger amounts of plume are generated 3 3,15,26. The prefilter captures larger particles, the charcoal filter will remove toxic gases and odour while the ULPA filtration forces matter through a depth filter that is similar to a maze 2,3,15,26. Using high efficiency particulate air filters 
(HEPA), ventilation exhausts and smoke evacuators is recommended to reduce exposure to the harmful effects of surgical plume and effectively purify the air in the operating room ${ }^{13,14,27-29}$. Laparoscopic smoke can be evacuated through a special laparoscopic smoke evacuation device $2,3,6,13-15,30$.

\section{Infection control}

According to the literature, the simple act of wearing a surgical face mask will generally filter particles to about 5 microns in size, while a high-filtration mask such a laser mask can filter particles to about 0.1 micron 2,10,14,15,23,27,31-33. Wearing gloves and a mask when disposing of smoke evacuator filters is also a vital control measure in reducing the transmission of infectious agents. Despite the benefits, Edwards and Reiman ${ }^{34}$ state that the use of personal protection equipment (PPE) is low.

\section{Compliance}

\section{Knowledge}

Both Tregoning ${ }^{35}$ and Khoshdel et al. ${ }^{36}$ noted that there was a fundamental lack of understanding of the potential health risks from exposure to surgical plume, and recommended continuous professional development to improve staff knowledge about the risks to health and the use of local exhaust ventilation (LEV). The focal point of this exercise is to improve behaviours and practices in relation to the use of smoke evacuation tools and infection control procedures - a priority for perioperative nurses even in a general sense ${ }^{37}$. Educating perioperative staff about the dangers of surgical smoke will support a culture whereby smoke evacuation is seen as a necessity and a key factor for workplace safety 2,11,23,38-43. Staff education should encompass the hazards of surgical smoke, infection prevention and methods to minimise or eliminate surgical plume ${ }^{15,27}$. A study by Ball ${ }^{44}$ noted that compliance with smoke evacuation practices increased when nurses received training and education about the hazards of surgical smoke and methods of evacuating it. Chavis et al. ${ }^{45}$ demonstrated that an improvement in staff knowledge correlated with increased use of surgical smoke management systems. Dawes ${ }^{46}$ recommended that perioperative nurses become experts in the use of available tools to minimise exposure to surgical smoke. To assist with this education the smoke evacuator manufacturers ${ }^{40}$ should be invited to provide regular in-service and onsite training.

\section{Attitudes and barriers}

According to Marsh ${ }^{40}$ and Giordano ${ }^{47}$, the cost of a smoke evacuation system, the significant price difference between a standard facemask and a high filtration one, misconception by staff that a standard facemask will provide sufficient protection against inhaling surgical smoke and a lack of knowledge about the dangerous risk of surgical smoke are all barriers to implementing efficient smoke evacuation procedures and taking preventive measures. Ball ${ }^{44}$ stated that the greatest barriers to implementing smoke evacuation practices were the unavailability of smoke evacuation equipment, the refusal by surgeons to allow smoke evacuation devices to be used, the noise produced by the smoke evacuators and the complacency of perioperative staff. Bigony ${ }^{22}$ and Lewin et al..$^{10}$ state that resistance to smoke evacuation can be attributed to expense, inconvenience, time constraints and a general lack of knowledge regarding the potential hazards associated with surgical plume exposure. Steege et al. ${ }^{48}$ reported that the most frequent reasons for not using LEV and PPE during laser surgery and electrosurgery were "not part of the protocol', 'not provided by the employer', 'exposure was minimal', 'not readily available in work area'. One 'other' reason for using a mask was when a patient had a known infectious disease, hence the most common 'other' reason for not using a respirator during electrosurgery was prior confirmation of the patient not carrying an infectious agent.

\section{Role modelling and support}

A cross-sectional survey conducted in the United States indicated that strong support from management was a key component to improved compliance ${ }^{49}$. Chavis et al..$^{45}$ found that perioperative managers who were supportive of education programs and had allocated funds and time to support and encourage staff members to participate during their regularly scheduled work hours and over the year had also adopted and established best practice for the management of surgical plume in the operating room. This is further supported by Ball ${ }^{50}$ who found that appropriate smoke evacuation practices improved when leaders supported the use of smoke evacuators.

\section{Discussion}

Improving compliance with best practice management of surgical plume in the operating theatre can be achieved through staff education and a supportive leadership team. Education should include evidencebased practices and strategies ${ }^{44,51-53}$ whereby nurses gain the essential skills to effect change within the perioperative environment. Support from management can also positively transform the working environment ${ }^{54}$ enabling perioperative nurses to act as advocates, for both patients 


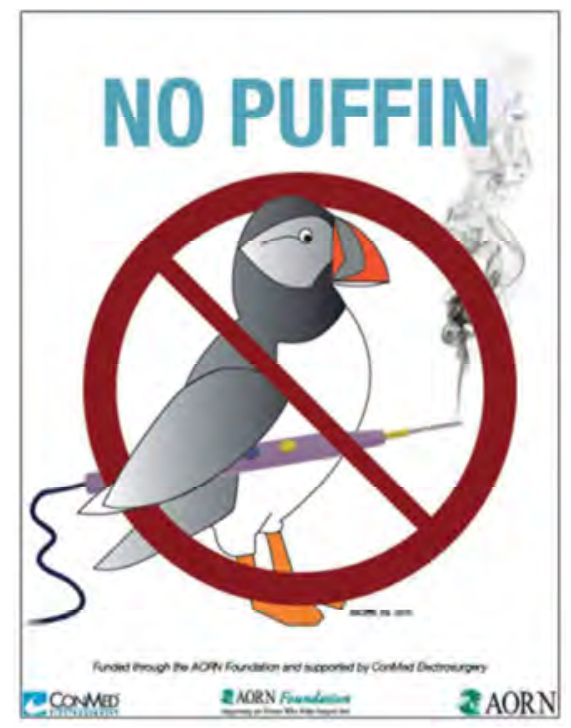

and the surgical team, to promote appropriate strategies including the use of smoke evacuation systems and PPE. The clinical nurse / team leader of the various surgical disciplines are the most suitably qualified personnel to educate their team members and promote best practice. Additionally, regular audits are recommended to ensure staff members are compliant with the use of smoke evacuation systems and PPE.

Regular in-service education sessions conducted by sales representatives can help staff members acquire or update knowledge about the hazards of surgical plume and the various devices to evacuate surgical plume.

Informative posters can be displayed in operating theatres, staff rooms and along theatre corridors to attract staff attention.

Policies that are simple and easy to follow should be developed to guide perioperative staff in creating an environment that reduces the exposure of patients and perioperative personnel to surgical plume ${ }^{55-57}$. Health care site policy should articulate that when surgical plume is generated smoke will be captured and filtered through the use of smoke evacuators or in-

\section{Are You Still Smoking in the OR?} Using an electrosurgery device on one gram of tissue is like inhating
the smoke from 6 unfiltered cigarettes in 15 minutes.'

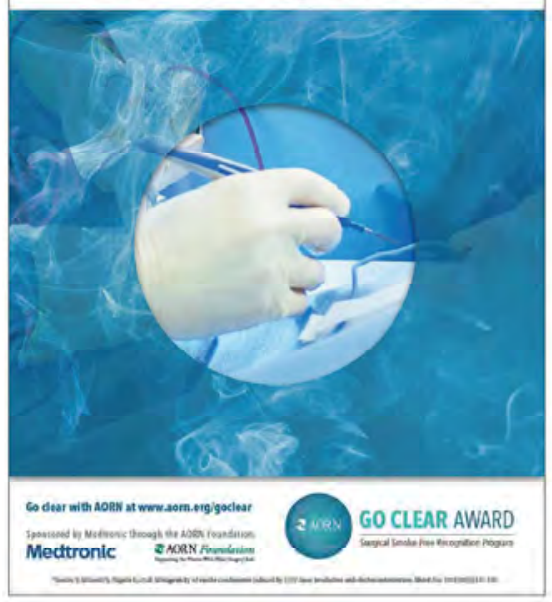

line filters positioned on suction lines ${ }^{55-57}$. The policy should also state that smoke evacuation devices or equipment must be listed on all surgeon procedure cards for procedures that produce any surgical smoke ${ }^{44}$. Smoke evacuation policies must be communicated to all perioperative staff ${ }^{44}$. Compliance with smoke evacuation policies should be monitored as part of the quality improvement process ${ }^{2,44}$.

\section{Conclusion}

The literature describes the hazards of surgical plume and concerns around the lack of compliance with prevention strategies. Since surgical plume is a controllable environmental occupational hazard, efforts to eliminate it can help to minimise health costs and improve the health of perioperative personnel and patients. Regular education sessions to assist staff to understand the danger of surgical plume and preventative measures can be an effective way to minimise exposure to surgical plume and improve compliance with using personal protection and smoke evacuation equipment.

\section{References}

1. Discover the reasons for a surgical smoke free zone [Internet]. Lancaster: Buffalo Filter [cited 2015 July 30]. Available from www.buffalofilter.com/education-articles/

2. Ulmer BC. The hazards of surgical smoke. AORN J 2008;87(4):721-728.

3. Ball, K. Update for anesthetic nurses. Part 1. The hazards of surgical smoke. AANA J 2001;69(2):125-132.

4. Buffalo Filter. Why is surgical smoke plume so hazardous? [Internet]. Lancaster: Buffalo Filter [cited 2015 July 30]. Available from: www. buffalofilter.com/files/7914/1443/3525/ Website_Training_Education_ Section_10_27_2014.pdf

5. Spearman J, Tsavellas G, Nichols P. Current attitudes and practices towards diathermy smoke. Ann R Coll Surg Eng 2007;89(2):162165.

6. Lynch J. The ABCs of surgical smoke plume [Internet]. Surgical products; 2009 [cited 2015 July 30]. Available from www. surgicalproductsmag.com/news/2009/abcssurgical-smoke-plume.

7. Mowbray N, Ansell J, Warren N, Wall P, Torkington J. Is surgical smoke harmful to theater staff? A systematic review. Surg Endosc 2013;27(9):3100-3107.

8. Association of Perioperative Practice (AfPP). Surgical smoke: What we know [Internet]. Harrogate: AfPP); 2009 [cited 2015 July 30]. Available from http://www.afpp.org.uk/ filegrab/1smokeplume-Final1.pdf? ref=1112.

9. Benson SM, Novak DA, Ogg MJ. Proper use of surgical $N 95$ respirators and surgical masks in the OR. AORN J 2013;97(4):457-467.

10. Lewin JM, Brauer JA, Ostad A. Surgical smoke and the dermatologist. J Am Acad Dermatol 2011;65(3)636-641.

11. Romig CL, Smalley PJ. Regulation of surgical smoke plume. AORN J 1997;65(4):824-828.

12. Alp E, Bijl D, Bleichrodt RP, Hansson B, Voss, A. Surgical smoke and infection control. Hosp Infect 2006;62(1):1-5.

13. Carbajo-Rodriguez H, Aguayo-Albasini JL, Soria-Aledo V, Garcia-Lopez C. Surgical smoke: Risks and preventive measures. Cir Esp 2009;85(5):274-279.

14. Fan JKM, Chan FSY, Chu KM. Surgical smoke. Asian J Surg 2009;39(4):253-7.

15. Ball, K. Controlling surgical smoke: A team approach. IC Medical Inc Informational Booklet n.d.

16. Polit DF, Beck CT. Essentials of Nursing Research: Methods, Appraisal, and Utilization. $6^{\text {th }}$ ed. Philadelphia: Lippincott Williams \& Wilkins; 2006.

17. Campbell Collaboration. What is a systematic review? [Internet]. Oslo: 
Campbell Collaboration; 2017 [cited 2017 March 29]. Available from www.campbellcollaboration.org/researchresources/writing-a-campbell-systematicreview/systemic-review.html.

18. Cochrane Consumer Network. What is a systematic review? [Internet]. London: Cochrane Consumer Network; 2017 [cited 2017 March 29]. Available from http:// consumers.cochrane.org/whatsystematic-review.

19. Hill DS, O'Neill JK, Powell RJ, Oliver, DW. Surgical smoke - A health hazard in the operating theatre: A study to quantify exposure and a survey of the use of smoke extractor systems in UK plastic surgery units. J Plast Reconstr Aesthet Surg 2012;65(7):911916.

20. Nascent Surgical. Prioritizing Surgical Plume [Internet]. Eden Prairie; Nascent Surgical; 2017 [cited 2017 Feb 16]. Available from http:// nascentsurgical.com/surgicalsmoke/prioritizing-surgical-plume/

21. Baggish MS, Baltoyannis P, Sze E. Protection of the rat lung from the harmful effects of laser smoke. Lasers Surg Med 1988;8(3):248253

22. Bigony L. Risks associated with exposure to surgical smoke plume: A review of the literature. AORN J 2007;86(6):1013-1020.

23. Rimmer, V. Diathermy smoke plume: why do we put up with it? J Perioper Pract 2009;19(12):424-427.

24. Weld KJ, Dryer S, Ames CD, Cho K, Hogan $C$, Lee $\mathrm{M}$ et al. Analysis of surgical smoke produced by various energy-based instruments and effect on laparoscopic visibility. J Endourol 200;21(3):347-351.

25. Matthews S. Preventing harm from surgical plume. Kai Tiaki: Nursing New Zealand 2016;22(6):26-27

26. Management of surgical smoke tool kit: Surgical smoke evacuation (part IV) [Internet]. Denver: Association of Perioperative Registered Nurses (AORN); [cited 2017 April 20]. Available from www. aorn.org/guidelines/clinical-resources/ tool-kits/management-of-surgical-smoketool-kit

27. Karsai S, Daschlein G. 'Smoking guns': Hazards generated by laser and electrocautery smoke. J Dtsch Dermatol Ges. 2012;10(9):633-636.

28. Scott E, Beswick A, Wakefield, K. The hazards of diathermy plume. Br J Perioper Nurs 2004;14(9):409-414.
29. Walczak DA, Grobelski B, Pasieka Z. 'There is no smoke without a fire' - Surgical smoke and the risk connected with it. Pol Przegl Chir 2011;83(11):634-639.

30. Kwak HD, Kim SH, Seo YS, Song KJ. Detecting hepatitis B virus in surgical smoke emitted during laparoscopic surgery. Occup Environ Med 2016;73(12):857-863.

31. Management of surgical smoke tool kit: Additional perioperative nursing care (part V) [Internet]. Denver: Association of Perioperative Registered Nurses (AORN); [cited 2017 April 20]. Available from www. aorn.org/guidelines/clinical-resources/ tool-kits/management-of-surgical-smoketool-kit.

32. King CA. Health care worker safety in surgery. AORN J 2011;94(5):457-468.

33. Lindsey C, Hutchinson M, Mellor G. The nature and hazards of diathermy plumes: $A$ review. AORN J 2015;101(4):428-442.

34. Edwards BE, Reiman RE. Comparison of current and past surgical smoke control practices. AORN J 2012;95(3):337-350.

35. Case study: protection of healthcare staff from surgical smoke in operating theatres. Sutton: Tregoning C; 2015 [cited 2017 March 21]. Available from www. personneltoday. $\mathrm{com} / \mathrm{hr} /$ case-study-protection-ofhealthcare-staff-from-surgical-smoke-inoperating-theatres/.

36. Khoshdel H, Amouzeshi A, Amouzeshi Z, Unesi Z. Surgical team knowledge about electrocautery smoke complications in the educational hospitals in Birjand, 2011 Journal of Surgery and Trauma, 2014:2(1):17-20.

37. Kang E, Gillespie BM, Massey D. What are the non-technical skills used by scrub nurses?: An integrated review. ACORN 2014;27(4):16-25.

38. Criscitelli, T. Human factors engineering: Its place and potential in OR safety. AORN J 2015;101:571-573.

39. Smalley $P$, Cubitt J. Clear air in surgery - a new ACORN initiative. ACORN 2015;28(3):38-39.

40. Marsh S. The smoke factor: things you should know. J Perioper Pract 2012;22(3):91-94.

41. Battie R, Steelman VM. Accountability in nursing practice: Why it is important for patient safety. AORN J 2014;100(5):537-541.

42. Davies M, Shaw E. Safer Australian surgical teamwork - a multidisciplinary human factors project. ACORN 201;27(4):42-44.
43. Sinnott MJ, Eley RM. Staff safety first - a priority in the operating room. ACORN 2015;28(2):8-11.

44. Ball, K. Compliance with surgical smoke evacuation guidelines: implications for practice. AORN J 2010;92(2):142-149.

45. Chavis S, Becker M, Jamias MS. Clearing the air about surgical smoke: An education program. AORN J 2016;103(3):289-296.

46. Dawes BSG. Stop smoke campaign begins with you. AORN J 2000;72(5):768-770.

47. Giordano BP. Don't be a victim of surgical smoke. AORN J 1996;63(3)520-522.

48. Steege AL, Boiano JM, Sweeney MH. Secondhand smoke in the operating room? Precautionary practices lacking for surgical smoke. Am J Ind Med 2016;59(11):1020-1031.

49. Holmes S. Factors affecting surgical plume evacuation compliance. ACORN 2016;29(4):39-42.

50. Ball, K. Surgical smoke evacuation guidelines: compliance among perioperative nurse. AORN J 2010;92(2):e1-e23.

51. Duff J, Butler M, Davies M, Williams R, Carlile J. Perioperative nurses' knowledge, practice, attitude, and perceived barriers to evidence use: A multisite, cross-sectional survey. ACORN J 2014;27(4):28-35.

52. Duff J, Butler M, Davies M, Williams R, Carlile J. Factors that predict evidence use by Australian perioperative nurses. ACORN 2016;29(2):24-29.

53. Gillespie, BM. ACORN: Promoting an evidence-based culture through recognition of the contribution of research to perioperative practice. ACORN 2014;27(3):4-5.

54. Waddell AW. Cultivating quality: implementing surgical smoke evacuation in the operating room. Am J Nurs 2010;110(1)54-58.

55. Association of Perioperative Registered Nurses (AORN). 'Recommended practices for electrosurgery' in Perioperative standards and recommended practices, pp. 134-135. AORN 2013.

56. Association of Perioperative Registered Nurses (AORN). 'Recommended practices for laser safety in perioperative settings' in Perioperative standards and recommended practices, pp. 147-148. AORN 2013.

57. Association of Perioperative Registered Nurses (AORN). 'Recommended practices for minimally invasive surgery' in Perioperative standards and recommended practices, $\mathrm{p}$. 168. AORN 2013 